EDITORIAL

\title{
Space and the environment: an introduction to the topical collection
}

\author{
Amitrajeet A. Batabyal ${ }^{1} \cdot$ Henk Folmer $^{2,3}$ \\ Published online: 21 January 2019 \\ (c) Springer-Verlag GmbH Germany, part of Springer Nature 2019
}

\begin{abstract}
We have two objectives in this topical collection of papers. First, we bring together in one place, original research that sheds light on the ways in which the notion of "space" affects the conceptualization of natural resource and environmental problems. Second, given this conceptualization, we show how rigorous modeling of natural resource and environmental problems that explicitly accounts for space overcomes some of the shortcomings of non-spatial analysis. Following this introductory paper, there are five additional papers in this topical collection. Each of these papers discusses a particular research question at the interface of what we call "space and the environment."
\end{abstract}

Keywords Biased and inconsistent estimators · Environment $\cdot$ Modeling $\cdot$ Natural resources $\cdot$ Space $\cdot$ Welfare

JEL Classification Q50 - R11

\section{The spatial dimension of environmental and resource problems}

In the post-World War II era, regional scientists, geographers, regional economists, and others have been studying the notion of space and its myriad ramifications on people's lives (Isard 1956). Despite their great and laudable interest in spatial

Amitrajeet A. Batabyal

aabgsh@rit.edu

Henk Folmer

h.folmer@rug.nl

1 Department of Economics, Rochester Institute of Technology, 92 Lomb Memorial Drive, Rochester, NY 14623-5604, USA

2 College of Economics and Management, Northwest Agricultural and Forestry University, 3 Taicheng Road, Yangling Qu, Xianyang Shi 712100, Shaanxi Sheng, China

3 Department of Economic Geography, University of Groningen, Landleven 1, 9747 AD Groningen, The Netherlands 
matters, these scientists dealing with spatial issues have been less keen to rigorously model and analyze environmental and natural resource (henceforth ER) problems even though many such problems have a distinct spatial dimension to them. ${ }^{1}$ However, as noted by, amongst others, Batabyal and Nijkamp (2003), this insalubrious state of affairs has begun to change and therefore we now observe a steady increase in modeling-based research on ER problems in, inter alia, regional science and ER economics. $^{2}$

Inspired by the justly famous pre-World War II research of Hotelling (1931), standard textbooks by Fisher (1981), Hartwick and Olewiler (1998), and others show how ER economists have systematically analyzed the temporal dimension of resource utilization. As such, there is now a well-established tradition of analyzing the optimal intertemporal use of exhaustible resources such as coal and oil and the management of renewable resources such as forests, fisheries, and rangelands. ${ }^{3}$

This venerable tradition notwithstanding, Albers et al. (2010) pointed out that ER economists have gradually become increasingly interested in problems where space matters in the last three decades. Two salient factors have led to this increased interest. First, the contributions of researchers such as Holling (1973, 1996), Perrings (1996), and Batabyal et al. (2003), working in the field now known as ecological economics, have convinced most mainstream ER economists that natural resources in general and renewable resources in particular ought to be viewed as jointly determined by factors that are partly economic, partly ecological, and partly spatial in nature. In particular, full understanding of and predictions about ER problems require analysis of both their temporal and spatial dimensions as well as of time-space interactions (see Jaya et al. 2017, 2018). In other words, a comprehensive analysis of an ER problem and related policy require insight into three types of locations: (1) the origin where it is generated, (2) its dispersion and deposition, and (3) a valuation of the impacts at the origin and at the location of its deposition. In this regard, ignorance of the spatial or of the space-time dimensions not only leads to incomplete insight into the nature of the problem but also to biased and inconsistent estimators of the parameters of the non-spatial dimensions due to omitted variables.

Recognition of this last point has led ER economists to explicitly study-in addition to time - the role that space plays in their models of, inter alia, natural resource management. Second and as pointed out by Albers et al. (2010) and Ando and Baylis (2014), the development of geographical information system (GIS) data sets has now made it possible to comprehend the use, the benefits, and the management of natural and environmental resources in novel ways.

\footnotetext{
${ }^{1}$ For an overview of Isard's view on the spatial dimensions of ER problems, see Rose et al. (2014).

2 See Batabyal and Nijkmap $(2003,2009)$ and the many references in these two contributions for additional details on this point.

${ }^{3}$ See Dasgupta and Heal (1979) for more on exhaustible resources, Gordon (1954), Clark (1990), and Batabyal (2004) for more on fisheries and rangelands, and Van Kooten and Folmer (2004) for more on land and forest economics.
} 
The discussion in the preceding three paragraphs yields two conclusions. First, regional scientists, geographers, and others who have historically focused primarily on spatial problems have now begun to study natural resource and environmental problems. Second, ER economists, who have traditionally focused on the temporal dimension of resource utilization and management problems have now started addressing the spatial characteristics of such problems.

The five papers in this topical collection demonstrate some of the progress that has been made in the last three decades in rigorously modeling and analyzing problems at the interface of what we call "space and the environment." The individual papers cover a variety of topics and, in addition, they utilize different analytical techniques. In what follows, we group the five papers into two broad categories. The first three papers concentrate on ER problems in regions that are all located within a single nation. The second two contributions deal with ER problems in regions that are situated in different nations. That said, in all five papers, the word "region" refers to sub-national geographic entities. ${ }^{4}$

With this preliminary discussion out of the way, we now proceed to succinctly comment on the intellectual contributions of the individual papers that comprise this topical collection. To this end, we first focus on the three papers that concentrate on regions located within a single nation.

\section{Regions in a single nation}

\subsection{Sweden}

Hage et al. (2018) address the European Union's stated desire to promote the transition to a circular economy in which the value of products, materials, and resources are conserved for as long as reasonably possible. Next, this paper points to the salience of recycling in the transition to a circular economy and then analyzes differences in household recycling outcomes across the different municipal jurisdictions in Sweden. A key aim of this paper is to investigate how these outcomes can be connected not only to geographic and demographic conditions but also to differences in waste management policies.

The authors use data across 282 Swedish municipalities for the year 2005 to conduct econometric analyses and thereby contribute to the extant literature in two ways. First, they point to the regional heterogeneity in plastic packaging waste recycling across the different municipalities and then ask whether the existing Swedish policy design is both effective and cost-effective from a spatial perspective. Second, they analyze whether there is any spatial dependency in waste collection rates across the municipalities in Sweden.

The analysis conducted by the authors leads to several interesting findings. For instance, they show that plastic waste collections are higher in municipalities that

\footnotetext{
4 This is also the manner in which the word "region" is typically used in the contemporary regional science literature.
} 
employ weight-based management fees as opposed to flat fees. They also find that curbside recycling increases along with a higher number of drop-off stations. Second, there are no noteworthy correlations between packaging waste collections and regional cost variables such as the distance to the recycling industry. Finally, even though plastic packaging waste is presently collected in a manner that is not costeffective, the relevant authorities need to understand that if they want to increase plastic waste collection rates then they need to focus on policy variables and not on demographic, geographic, and socio-economic variables.

\subsection{Trinidad and Tobago}

The work of Dasgupta (1996), Batabyal et al. (2003), and many others showed that the provision of ecosystem services is vital to the sustenance of life. Yet, relatively little work has been done to quantify the value of these ecosystem services, particularly in what Ghermandi et al. (2018) call "small island developing states" or SIDS. Given this state of affairs, the authors concentrate on measuring and spatially mapping the economic value of selected ecosystem services in Trinidad and Tobago.

The three specific ecosystem services that Ghermandi et al. (2018) focus on are carbon sequestration by coastal ecosystems, coastal recreation, and coastal protection. Because of the severe lack of primary data sources, the authors utilize a variety of secondary sources along with benefit-transfer techniques and GIS data to conduct a spatial economic analysis of the value of the above three ecosystem services. This analysis reveals that the mean value of carbon sequestration is US $\$ 65 /$ hectare/year, of coastal recreation is US\$6468/hectare/year, and of shoreline coastal protection is US $\$ 924 /$ hectare/year.

How might these results be used to inform policy decisions? The authors point to three possible uses. First, they observe that these results can be used to ascertain which areas within Trinidad and Tobago ought to be protected most because of the high economic value of their ecosystem services. Second, one can create what the authors refer to as "vulnerability maps" where vulnerability refers to a specific area's overall dependence on a particular ecosystem service. Finally, the above numerical results can be used to identify areas that provide the highest combined economic value for all the three ecosystem services under study. Once this has been done, such areas can be used, for instance, to create nature conservation parks.

\subsection{United States of America}

Oliver and Khanna (2018) investigate the nature of electricity generation in the United States (US). They note that there is no coherent renewable energy policy in the US because even though 29 states are presently implementing heterogeneous renewable portfolio standards (RPSs), the remaining states have no renewable energy policy. This paper has three objectives. First, the authors determine the welfare cost of a national RPS relative to the existing state RPSs that achieve the same level of renewable energy generation. Second, they analyze the pros and cons of achieving a certain level of greenhouse gas (GHG) emissions with a national RPS as 
compared to a GHG cap-and-trade program. Finally, they study the relative merits of existing state RPSs, a national RPS, and a national GHG cap-and-trade policy.

The analysis is conducted using the so called BEPAM-E model which is a nonlinear, intertemporal, multi-region, partial equilibrium mathematical programming model that includes international trade with the rest of the world and effectively simulates the US agricultural, transportation fuel, and electric power sectors. The interdisciplinary nature of the modeling exercise stems from the fact that the market equilibrium is determined in the BEPAM-E model by maximizing the sum of consumer and producer surpluses in the three sectors subject to a plethora of policy and technological constraints along with material balance constraints.

The three policies under consideration have dramatically different impacts. Whereas the state RPSs increase total electricity generation in the pertinent time period, the national RPS has no impact on total electricity generation, and the national GHG cap-and-trade policy leads to a reduction in total electricity generation in the same time period. With regard to the welfare costs of the three policies, particularly interesting is what the authors find about the spatial distribution of the induced changes in consumer and producer surplus. Specifically, the state level RPSs lead to a decrease in consumer surplus in many of the regions that have more strict RPSs, while producer surplus in these same regions rises. The nature of the change in economic surplus is more uniform with a national RPS in the sense that consumer surplus declines in all regions and producer surplus rises in most regions because of the rise in the average price of electricity. Finally, the national GHG cap-and-trade policy leads to the most pronounced change in economic surplus; consumer surplus declines in all regions and producer surplus rises in all regions because of the relatively large increase in the average price of electricity. The findings of Oliver and Khanna (2018) clearly demonstrate the inefficiency of regional policies compared to national policies that typically offer greater flexibility in both the abatement options and in the spatial location of abatement targets.

We now briefly discuss the two papers that analyze natural ER problems in regions that are situated in different nations.

\section{Regions in multiple nations}

\subsection{Brazil and Chile}

The central question analyzed by Aroca et al. (2018) concerns the impact that changes in the spatial concentration of economic activity have on national economic growth in Brazil and Chile. Because of data limitations, it is not possible to analyze the above question directly and therefore the authors utilize a two-step methodology to shed light on this same question.

In the first step, they econometrically estimate the relationship between regional economic growth and a set of explanatory variables in the 1980-2010 time period that includes population density and the natural resource of interest to them. In the second step, the authors estimate the effect on national economic growth of 
the actual changes in the population concentration during the pertinent estimation period.

The logic of this two-step methodology is as follows. Changes in the population in specific regions within Brazil and Chile produce changes in population densities and this, in turn, alters the national metrics of regional population concentration. With these new densities, the authors recompute the economic growth in the various regions being studied and this recomputation gives rise to an economic growth estimate for Brazil and Chile which, as it turns out, is a weighted average of the economic growth in the individual regions.

In Chile, where regional population concentrations have grown in the 1980-2010 time period, the results show that this concentration has resulted in the loss of about one percent in the growth rate of gross domestic product (GDP). The results are similar for Brazil except that the strength of this loss is somewhat attenuated by the fact that there is no "metro Santiago effect" that is observed in the Chilean data. These and other results obtained in this paper are useful because they can be used to shed light on what the authors call "deconcentration policies" and on the desirability of place-based policies.

\subsection{Europe, Japan, and the United States of America}

Ever since the statement of the so called Porter (1991) hypothesis, researchers have been interested in analyzing the nexuses between environmental regulations and firm performance. This notwithstanding, Aldeiri and Vinci (2018) point out that at least in the context of environmental technologies, there is a dearth of empirical studies that analyze how knowledge spillovers influence innovation in and the productivity of such technologies. Given this lacuna in the extant literature, their purpose is to investigate the ways in which spillovers from innovation in what the authors call "energy production efficiency activities" affect the productivity of large multinational firms located in Europe, Japan, and the US.

Using data from the Organization for Economic Cooperation and Development's (OECD) REGPAT database, the authors first contend with some econometric issues and they then use alternate techniques to estimate a regression equation that links firm productivity measured by net sales in a particular year to a variety of independent variables such as the number of employees, the research and development (R\&D) capital stock, and, most importantly, the spatial technology spillover.

The results obtained by the authors show that whereas all the pertinent inputs under consideration have a positive effect on firm productivity, the spatial technology spillover variable has a negative impact in all three studied areas. Aldieri and Vinci (2018) believe that this negative impact arises possibly because of a "market competitiveness" effect but they are unable to adequately explain this result. Therefore, they wisely call for additional research on this question and note that it may be more meaningful to compute spillovers by using the distribution of firm patents and not simply the patent applications of firms.

Acknowledgements Batabyal acknowledges financial support from the Gosnell endowment at RIT. The usual disclaimer applies. 


\section{References}

Albers, H.J., Ando, A., Shogren, J.F.: Introduction to spatial natural resource and environmental economics. Resour. Energy Econ. 32, 93-97 (2010)

Ando, A.W., Baylis, K.: Spatial environmental and natural resource economics. In: Fischer, M.M., Nijkamp, P. (eds.) Handbook of Regional Science, pp. 1029-1048. Springer, Berlin (2014)

Batabyal, A.A.: Stochastic Modeling in Range Management. Nova Science Publishers, Hauppauge (2004) Batabyal, A.A., Kahn, J.R., O’Neill, R.V.: On the scarcity value of ecosystem services. J. Environ. Econ. Manag. 46, 334-352 (2003)

Batabyal, A.A., Nijkamp, P.: The environment in regional science: an eclectic review. Pap. Reg. Sci. 83, 291-316 (2003)

Batabyal, A.A., Nijkamp, P.: Sustainable development and regional growth. In: Capello, R., Nijkamp, P. (eds.) Handbook of Regional Growth and Development Theories, pp. 282-301. Edward Elgar, Cheltenham (2009)

Clark, C.W.: Mathematical Bioeconomics, 2nd edn. Wiley, New York (1990)

Dasgupta, P.: The economics of the environment. Environ. Dev. Econ. 1, 387-428 (1996)

Dasgupta, P., Heal, G.: Economic Theory and Exhaustible Resources. Cambridge University Press, Cambridge (1979)

Fisher, A.C.: Resource and Environmental Economics. Cambridge University Press, Cambridge (1981)

Gordon, H.S.: The economic theory of a common-property resource: the fishery. J. Polit. Econ. 62, 124142 (1954)

Hartwick, J.M., Olewiler, N.D.: The Economics of Natural Resource Use, 2nd edn. Addison-Wesley, Reading (1998)

Holling, C.S.: Resilience and stability of ecological systems. Annu. Rev. Ecol. Syst. 4, 1-23 (1973)

Holling, C.S.: Engineering resilience versus biological resilience. In: Schulze, P.C. (ed.) Engineering within Ecological Constraints, pp. 31-43. National Academy Press, Washington, DC (1996)

Hotelling, H.: The economics of exhaustible resources. J. Polit. Econ. 39, 137-175 (1931)

Isard, W.: Location and Space-Economy. MIT Press, Cambridge (1956)

Jaya, I.G.N.M., Folmer, H., Ruchjana, B.N., Kristiani, F., Andriyana, Y.: Modeling of infectious diseases: a core regional research topic for the next hundred years. In: Jackson, R., Schaeffer, P. (eds.) Regional Research Frontiers, vol. 2, pp. 239-255. Springer International Publishing, Cham (2017)

Jaya, I.G.N.M., Folmer, H., Kristiani, F., Ruchjana, N.: The relative risk of Dengue disease: Bayesian spatiotemporal analysis, forecasting, and mapping (under review) (2018)

Perrings, C.: Ecological resilience in the sustainability of economic development. In: Faucheux, S., Pearce, D., Prroops, J. (eds.) Models of Sustainable Development, pp. 231-252. Edward Elgar, Cheltenham (1996)

Porter, M.: America's Green Strategy. Sci. Am. 264, 168 (1991)

Rose, A., Folmer, H., Nijkamp, P.: Walter Isard's contributions to environmental economics and ecological economics. Int. Reg. Sci. Rev. 37, 107-122 (2014)

van Kooten, G.C., Folmer, H.: Land and Forest Economics. Edward Elgar, Cheltenham (2004) 